\title{
TOLERÂNCIA GENÉTICA DE LINHAGENS DE MILHO AOS HERBICIDAS TEMBOTRIONE E NICOSULFURON
}

\author{
ADILSON RICKEN SCHUELTER ${ }^{1}$, MAYARA FABIANA DA SILVA ${ }^{1}$, \\ ISABEL REGINA PRAZERES DE SOUZA², JONATAS MARCOLIN ${ }^{1}$ e IVAN SCHUSTER ${ }^{1}$
}

\author{
${ }^{1}$ Cooperativa Central de Pesquisa Agrícola, Cascavel, PR, Brasil. \\ adilson_schuelter@yahoo.com.br,mayara@hotmail.com,jonatas_marcolin@hotmail.com,ivanschuster.ivan@gmail.com \\ ${ }^{2}$ Embrapa Milho e Sorgo, Sete Lagoas, MG, Brasil-isabel.prazeres@embrapa.br
}

Revista Brasileira de Milho e Sorgo, v.17, n.2, p. 317-327, 2018

\begin{abstract}
RESUMO - As plantas daninhas constituem um dos fatores que reduzem a produtividade do milho e, portanto, é importante conhecer o mecanismo de tolerância da cultura aos herbicidas, de forma a fornecer informações que minimizem os riscos de danos aos cultivos. Dessa forma, o objetivo do trabalho foi avaliar a resposta de linhagens de milho e o controle genético envolvido na tolerância aos herbicidas nicosulfuron e tembotrione. Duzentas e cinco linhagens de milho foram avaliadas quanto à reação aos herbicidas. Para a avaliação do controle genético de tolerância aos herbicidas foram empregadas duas linhagens tolerantes e duas sensíveis, as quais foram intercruzadas empregando um dialelo de meia tabela. As linhagens e as populações oriundas desses cruzamentos foram avaliadas quanto à reação aos herbicidas em delineamento de blocos casualizados com quatro repetições. As dosagens foram de $60 \mathrm{~g} \mathrm{ha}^{-1} \mathrm{de}$ nicosulfuron $\left(\operatorname{Sanson}^{\circledR}\right)$ e $100 \mathrm{~g} \mathrm{ha}^{-1}$ de tembotrione $\left(\operatorname{Soberan}^{\circledR}\right)$. A avaliação fenotípica constituiu-se de número de plantas sensíveis e/ou tolerantes e o teste do Qui-quadrado $\left(\chi^{2}\right)$ foi utilizado nas análises. Quanto à resposta à aplicação dos agroquímicos verificaram-se linhagens tolerantes ou sensíveis a ambos os herbicidas ou apenas a um deles. Nas avaliações do controle genético, as análises evidenciaram um gene com dominância completa que, pela análise de segregação das famílias F3, permitiu levantar a hipótese de genes fortemente ligados ou pleiotrópicos. Os resultados obtidos, associados ao retrocruzamento assistido por marcadores moleculares (RCAM), auxiliaram o processo de introgressão da tolerância nas linhagens sensíveis aos herbicidas nicosulfuron e tembotrione.
\end{abstract}

Palavras-chave: Zea mays L., herança, melhoramento genético, marcadores moleculares.

\section{GENETIC TOLERANCE OF MAIZE LINES TO TEMBOTRIONE AND NICOSULFURON}

\begin{abstract}
As weeds are one of the factors that reduce maize productivity it is important to know the mechanism of crop tolerance to herbicide in order to minimize the risk of damage to the plants. Thus, the objective of this work was to evaluate the response of maize inbred lines and the genetic control of the tolerance to the herbicides nicosulfuron and tembotrione. Two hundred and five maize inbred lines were evaluated for herbicides reaction. For the evaluation of the genetic control of tolerance to herbicides, two tolerant and two sensitive inbred lines were used, which were intercrossed using a half diallel table. The inbred lines and the populations obtained from these crosses were evaluated for reaction to the herbicides in a randomized complete block design with 4 replicates. The dosages were $60 \mathrm{~g}^{-1}$ of nicosulfuron (Sanson ${ }^{\mathrm{TM}}$ ) and $100 \mathrm{~g} \mathrm{ha}^{-1}$ of tembotrione (Soberan ${ }^{\mathrm{TM}}$ ). The phenotypic evaluation was based on the number of sensitive and / or tolerant plants and the chi-square test $(\chi 2)$ was used in the analysis. Regarding the response to the application of the agrochemicals, inbred lines were tolerant or sensitive to one or both herbicides. The analysis of genetic control showed a gene with complete dominance, and the segregation analysis of the F3 families hypothesized the occurrence of strongly linked or pleiotropic genes. The data obtained associated to marker-assisted backcrossing allowed the tolerance introgression in sensitive inbred lines to nicosulfuron and tembotrione.
\end{abstract}

Keywords: Zea mays L., inheritance, plant breeding, molecular markers. 
O sucesso do controle químico de plantas daninhas em lavouras de milho tem se destacado principalmente pela eficiência, pelo rendimento operacional e pelo custo-benefício (Dan et al., 2010). Dentre os herbicidas aplicados em pós-emergência disponíveis no mercado para a cultura do milho destaca-se o ingrediente ativo nicosulfuron, pertencente ao grupo químico das sulfoniluréias, que promove a inibição da enzima ALS - acetolactato sintase (Trezzi \& Vidal, 2001). Este herbicida possui ampla aplicabilidade, mas é necessário não negligenciar o híbrido, que pode apresentar elevada tolerância ao nicosulfuron e reduzida para outros herbicidas, sendo dependente do estádio fenológico no momento da aplicação e o intervalo entre a aplicação do herbicida e a do inseticida organofosforado, ou da adubação nitrogenada de cobertura (López-Ovejero et al., 2003). Como alternativa, tem crescido o uso de herbicidas inibidores de carotenoides, principalmente os que inibem a enzima HPPD - 4-hidroxifenilpiruvato desoxigenase (Hawkes, 2007), tais como o tembotrione. Este herbicida não exige manejo especial em relação à adubação com ureia em cobertura para a cultura do milho (Dan et al., 2009).

A resposta dos híbridos de milho à aplicação de herbicidas pós-emergentes do grupo das sulfoniluréias é bastante variável, de baixa a elevada tolerância (Cavalieri et al., 2008). Entretanto, os herbicidas com ingrediente ativo tembotrione aplicados em cultivos de milho têm sido seletivos, ou seja, altamente tolerante (Karam et al., 2009). No entanto, a aplicação desses herbicidas em campos de linhagens e de populações segregantes, obtidas a partir de alguns cruzamentos com genótipos tolerantes, tem revelado o aparecimento de sintomas de fitotoxicidade, indicando a existência de fatores genéticos que conferem sensibilidade ao nicosulfuron e tembotrione.
O conhecimento do controle genético de determinada característica é essencial no processo de seleção de genótipos de interesse, na definição de estratégias de melhoramento (Cruz et al., 2014) e no manejo a ser adotado pelos produtores para o controle das plantas daninhas (Vargas et al., 2001; Christoffoleti \& Ovejero, 2008; Dan et al., 2009). Os atributos genéticos de uma espécie podem ser qualitativos, governados por um ou poucos genes e apresentando classes fenotípicas facilmente distinguíveis umas das outras, ou quantitativos, determinados por vários genes e muito influenciados pelas condições de ambiente. Nesse contexto, a tolerância genética às diferentes classes de herbicidas tem sido atribuída à herança monogênica com dominância completa ou incompleta (Christoffoleti \& Ovejero, 2008), como o gene CYP, que controla a tolerância natural do milho, incluindo àqueles herbicidas a base de nicosulfuron (Pataky et al., 2009). Contudo, a influência de genes modificadores pode resultar na variação do padrão fenotípico que, segundo Délye et al. (2013), pode ser resultante do aumento da metabolização e/ou compartimentação da molécula herbicida, pela redução da absorção ou translocação diferencial. Liu et al. (2015), avaliando o transcriptoma de linhagens tolerantes e sensíveis submetidas a aplicação de nicosulforon, identificaram treze genes candidatos envolvidos na metabolização desse ingrediente ativo.

Quando a característica de interesse é qualitativa, condicionada por poucos genes e de alta herdabilidade, a sua introgressão tem sido realizada por meio de retrocruzamentos. Associado a isso, o advento dos marcadores moleculares, principalmente os SSR (sequências simples repetidas, microssatélites), e mais recentemente os marcadores SNP (polimorfismo de nucleotídeo único) tornou realidade o retrocruzamento assistido por marcadores em programas de melho- 
ramento genético (Ruane \& Sonnino, 2007; Jiang, 2015).

Dessa forma, o objetivo do trabalho foi avaliar a resposta de linhagens de milho à aplicação dos herbicidas tembotrione e nicosulfuron, bem como elucidar o controle genético associado à tolerância, visando à seleção de genótipos tolerantes a esses agroquímicos.

\section{Material e Métodos}

A experimentação foi realizada em três etapas na Estação Experimental da Cooperativa Central de Pesquisa Agrícola (Coodetec), Cascavel (PR): a) caracterização das linhagens quanto à resposta à aplicação dos herbicidas; b) elucidação do controle genético envolvido na tolerância; c) realização da introgressão da tolerância aos herbicidas, assistida por marcadores moleculares.

\section{Avaliação fenotípica da reação de linhagens de milho aos herbicidas}

Na safra de verão de 2012/13 foram semeadas 205 linhagens de milho do Programa de Melhoramento da Coodetec, em delineamento inteiramente casualizado com duas repetições, sendo cada linhagem representada por uma fileira de $5 \mathrm{~m}$, com espaçamento de $0,75 \mathrm{~cm}$ nas entrelinhas. Na semeadura utilizou-se $430 \mathrm{~kg} \mathrm{ha}{ }^{-1}$ do formulado 12-28-16 (NPK), sendo a adubação de cobertura realizada com $150 \mathrm{~kg} \mathrm{ha}^{-1}$ de ureia, sete dias após a aplicação dos herbicidas.

Para o controle de pragas e aplicação dos herbicidas utilizou-se um pulverizador contendo pontas AXI 110.03, distanciadas entre si de $0,5 \mathrm{~m}$, em pressão de trabalho de $300 \mathrm{kPa}$, constituindo volume de calda de $200 \mathrm{~L} \mathrm{ha}^{-1}$. A primeira aplicação de inseticida foi realizada imediatamente após o plantio com metomil (86 $\mathrm{g} \mathrm{ha}^{-1}$ ), sendo que no estádio V2 realizou-se a segunda aplicação com espinosade associado ao imidacloprid, nas doses de 48 e $110 \mathrm{~g} \mathrm{ha}^{-1}$, respectivamente. Os herbicidas ${ }^{1}$ foram aplicados nas linhagens de milho no estádio de V3 utilizando 60 e $100 \mathrm{~g} \mathrm{ha}^{-1}$ de nicosulfuron $\left(\right.$ Sanson $^{\circledR}$ ) e tembotrione $\left(\right.$ Soberan $^{\circledR}$ ), respectivamente. As aplicações dos herbicidas foram realizadas em 2,5 $\mathrm{m}$ de cada fileira empregando pulverizador costal motorizado e cortinas de contensão contra deriva.

No decorrer do desenvolvimento da cultura, irrigações por aspersão em sistema de carretel autopropelido foram realizadas, sendo uma logo após o plantio, com lâmina d'água de aproximadamente 10 $\mathrm{mm}$, e uma suplementar com $20 \mathrm{~mm}$, aos 7 dias após a aplicação dos herbicidas.

Para evitar dificuldades na identificação dos sintomas de fitointoxicação nas plantas, sendo os herbicidas sistêmicos, os experimentos foram realizados em áreas distintas. A avaliação fenotípica da reação das plantas aos herbicidas foi realizada aos 7 e 14 dias da aplicação (DAA), empregando a escala de notas descrita por Velini et al. (1995): A (sem injúrias); B (injúrias leves e/ou redução de crescimento com rápida recuperação); C (injúrias moderadas e/ou reduções de crescimento com lenta recuperação ou definitivas); D (injúrias severas e/ou reduções de crescimento não recuperáveis e/ou reduções de estande) e E (destruição completa da cultura ou somente algumas plantas vivas).

Os diferentes experimentos foram conduzidos em condições ambientais favoráveis considerando-se as médias de dados climatológicos e velocidade do vento no dia da aplicação dos herbicidas (Tabela 1), associados à irrigação suplementar.

${ }^{1}$ A menção do nome comercial não significa recomendação técnica por parte dos autores. 
Tabela 1. Médias de dados climatológicos dos períodos de condução dos experimentos e velocidade do vento no dia da aplicação dos herbicidas.

\begin{tabular}{cccccc}
\hline Experimento & $\begin{array}{c}\text { Temperatura } \\
\text { máxima }\left({ }^{\mathbf{0}} \mathbf{C}\right)\end{array}$ & $\begin{array}{c}\text { Temperatura } \\
\text { Media }\left({ }^{\circ} \mathbf{C}\right)\end{array}$ & $\begin{array}{c}\text { Temperatura } \\
\text { mínima }\left({ }^{\circ} \mathbf{C}\right)\end{array}$ & $\begin{array}{c}\text { Velocidade do } \\
\text { vento m/s }\end{array}$ & $\begin{array}{c}\text { UR } \\
(\%)\end{array}$ \\
\hline $\begin{array}{c}\text { Reação das } \\
\text { linhagens aos } \\
\text { herbicidas }\end{array}$ & 30,55 & 24,14 & 18,60 & 0,97 & 67,69 \\
$\begin{array}{c}\text { Controle } \\
\text { Genético da }\end{array}$ & 27,10 & 21,22 & 15,84 & 1,74 & 75,40 \\
$\begin{array}{c}\text { Tolerância aos } \\
\text { Herbicidas }\end{array}$ & & & & \\
$\begin{array}{c}\text { Avaliação das } \\
\text { Famílias F3 }\end{array}$ & 28,85 & 23,31 & 18,20 & 1,33 & 69,81 \\
\hline
\end{tabular}

\section{Controle genético da tolerância aos herbicidas}

Para a elucidação do controle genético da tolerância ao nicosulfuron e tembotrione foram selecionadas linhagens tolerantes (CD01_28 e CD02_06) e sensíveis (CD03_07 e CD04_72) do experimento de caracterização de linhagens. Essas linhagens foram cruzadas em esquema dialélico de meia tabela. A partir de cada população F1 foi obtida a respectiva população F2 e os retrocruzamentos com ambos os genitores, RC1F1. Dessa forma, para cada cruzamento entre as linhagens selecionadas foram obtidas três populações (F1, F2 e RC1F1).

As linhagens e as populações segregantes e não-segregantes foram avaliadas quanto à resposta aos herbicidas, em delineamento experimental de blocos casualizados com quatro repetições, na Safra de Verão 2013/14. As linhagens e as populações F1 e $\mathrm{RC} 1 \mathrm{~F} 1$ tiveram a parcela constituída de 4 fileiras de 5 $\mathrm{m}$ e as populações $\mathrm{F} 2$ de 8 fileiras de $5 \mathrm{~m}$. A aplicação dos herbicidas foi realizada nas mesmas condições do experimento de caracterização e a avaliação da fitointoxicação aos 14 DAA, conforme Velini et al. (1995) com algumas modificações: plantas tolerantes (conceitos A e B) e plantas sensíveis (conceitos C, D e E).

Além dos experimentos que envolveram a avaliação das gerações progenitoras, F1s, F2 e retrocruzamentos foram instalados dois experimentos adicionais na safra de verão 2014/15, contendo 189 famílias F3 oriundas do cruzamento entre as linhagens contrastantes, CD02_06 e CD03_07, respectivamente, tolerante e sensível a ambos os herbicidas. A parcela experimental foi constituída de uma fileira de $4 \mathrm{~m}$ com duas repetições, sendo uma para avaliação da resposta ao nicosulfuron e a outra ao tembotrione. Os dados de segregação dessas famílias F3 foram submetidos ao teste do qui-quadrado $\left(\chi^{2}\right)$.

\section{Retrocruzamento assistido por marcadores SSR}

Cento e oito plantas da geração RC1F1 do cruzamento entre as linhagens CD03_07 e CD02_06, respectivamente, sensível e tolerante a ambos os herbicidas, foram conduzidas em casa de vegetação com condições controladas de temperatura e umidade, e 
fenotipadas quanto à resposta ao nicosulfuron e tembotrione.

O DNA das plantas da geração RC1F1 foi extraído de tecido foliar, coletado empregando perfurador de papel, conforme metodologia descrita por Fernandes et al. (2015). Foram selecionados 12 marcadores SSR polimórficos entre os parentais e empregados para identificação das plantas com maior recuperação do parental recorrente.

As plantas RC1F1 selecionadas foram aquelas que apresentaram a maior recuperação do genoma do parental recorrente, ou seja, menor distância genética em relação ao recorrente, e tolerância aos herbicidas. Essas plantas selecionadas foram autofecundadas e avaliadas para confirmação da tolerância aos herbicidas.

\section{Resultados e Discussão}

Nas avaliações visuais de fitointoxicação pelo nicossulfuron realizadas aos 7 DAA as 205 linhagens de milho do Programa da COODETEC, 84\% apresentaram conceito A, 10,24\% B, 2,44\% C, 2,44\% D e $0,49 \% \mathrm{E}$ (dados não demonstrados). Cavalieri et al. (2012), verificaram aumento da fitotoxicidade em milho pipoca aos 7 DAA, porém na dosagem de 17,5 g $\mathrm{ha}^{-1}$. Aos 14 DAA houve decréscimo no percentual de linhagens sem sintomas (A), 70,73\%, e incremento nos números de genótipos com injúrias leves (B) 17,56\%, de sintomas moderados (C) 6,83\%, e de danos totais das plantas (E) 4,39\%. Esse aumento nas injúrias visuais pode ser atribuído ao efeito tardio do herbicida, corroborando os dados obtidos por Liu et al. (2015), que verificaram aos 7 DAA em linhagens sensíveis, a formação de manchas cloróticas e enrugamento das margens de folhas, que progrediram até a morte aos 14 DAA.
Aos 7 DAA, a resposta ao herbicida tembotrione, empregando as mesmas 205 linhagens elites, verificou-se que 72,14\% não apresentavam branqueamento foliar, sendo caracterizadas segundo Velini et al. (1995) como conceito A. Entretanto, aos 14 DAA, verificou-se aumento de $20,89 \%$ no número de linhagens sem sintomas, e decréscimo no número de linhagens com conceito B. Os outros conceitos mantiveram-se estáveis aos 7 e 14 DAA, apresentando 1,49\% de linhagens com conceito C, 2,49\% com conceito $\mathrm{D}$, não sendo detectada morte de plantas (conceito E) (dados não demonstrados). Esses resultados corroboram os obtidos por Constantin et al. (2006), que observaram redução de sintoma foliar em híbridos de milho a partir dos 17 DAA. Entretanto, nas linhagens de milho estudadas verificou-se redução na expressão do sintoma foliar ligeiramente mais precoce, constatada aos 14 DAA.

De forma geral, as linhagens analisadas foram tolerantes ao nicosulfuron e tembotrione, destacando-se as linhagens CD01_28 e CD02_06, enquanto que as linhagens CD03_07 e CD04_72 foram sensíveis a ambos os herbicidas. Além disso, três linhagens tolerantes ao tembotrione foram sensíveis ao nicosulfuron. Contudo, a tolerância ou a sensibilidade dupla aos herbicidas desperta interesse estratégico, uma vez que ambos apresentam diferentes mecanismos de ação. Esses resultados permitem aventar a possibilidade de ocorrência de ligação gênica ou pleiotropia na determinação da tolerância aos herbicidas, sendo necessária uma análise de segregação para elucidar a hipótese genética para o padrão fenotípico detectado nas linhagens de milho.

A resposta das linhagens elites aos herbicidas por apresentarem tolerância, CD01_28 e CD02_06, ou sensibilidade, CD03_07 e CD04_72, e suas respectivas populações segregantes e não-segregantes 
obtidas pelo esquema de cruzamentos dialélicos de meia tabela, permitiu inferir sobre o controle genético da tolerância ao nicosulfuron e tembotrione, por meio das proporções fenotípicas observadas e esperadas, comparadas pelo teste do $\chi^{2}$ (Tabelas 2 e 3 ).

As plantas das populações F1 oriundas do cruzamento entre linhagens tolerantes e sensíveis aos herbicidas nicosulfuron e tembotrione (Tabelas 2 e 3 ), não apresentaram sintomas visuais de fitointoxicação, indicando dominância genética para o caráter tolerância a esses herbicidas. Na população $\mathrm{F} 1$, resultante do cruzamento entre as linhagens sensíveis, 100\% das plantas mostrou-se sensível aos dois herbicidas, indicando que CD03_07 e CD04_72 apresentam o mesmo fator genético que condiciona a sensibilidade. Teste do Qui-quadrado de aderência das frequências observadas às esperadas de plantas tolerantes e sensíveis das populações F2, oriundas dos cruzamentos das linhagens tolerantes, CD01_28 e CD02_06, com as linhagens sensíveis, CD03_07 e CD04_72, apresentou probabilidade superior a $5 \%$ para a hipótese de segregação de 3:1. Esses resultados demonstram herança monogênica com dominância completa para tolerância aos herbicidas. A hipótese de um gene dominante responsável pela tolerância ao nicosulfuron e tembotrione (Tabelas 2 e 3 ) foi confirmada por

Tabela 2. Frequências observadas e esperadas para tolerância e sensibilidade ao herbicida nicosulfuron, valores de $\chi 2$ e respectivas probabilidades.

\begin{tabular}{|c|c|c|c|c|c|c|}
\hline \multirow{2}{*}{ Geração } & \multirow{2}{*}{$\begin{array}{l}\text { Genótipo } \\
\text { ou } \\
\text { População }\end{array}$} & \multicolumn{2}{|c|}{ Número de Plantas } & \multirow{2}{*}{$\begin{array}{c}\text { Proporção } \\
\text { Esperada } \\
(\mathrm{T}: \mathrm{S})^{*}\end{array}$} & \multirow{2}{*}{$\chi^{2}$} & \multirow{2}{*}{ Probabilidade } \\
\hline & & $\begin{array}{c}\text { Tolerantes } \\
\text { (T) }\end{array}$ & $\begin{array}{c}\text { Sensíveis } \\
\text { (S) }\end{array}$ & & & \\
\hline $\mathrm{P}_{1}$ & CD01_28 & 298 & 0 & $1: 0$ & - & - \\
\hline $\mathrm{P}_{2}$ & CD02_06 & 296 & 0 & $1: 0$ & - & - \\
\hline $\mathrm{P}_{3}$ & CD03_07 & 0 & 277 & $0: 1$ & - & - \\
\hline $\mathrm{P}_{4}$ & $\mathrm{CDO}^{-7} 72$ & 0 & 286 & $0: 1$ & - & - \\
\hline F1 & $\mathrm{P}_{1} \times \mathrm{P}_{2}$ & 304 & 0 & $1: 0$ & - & - \\
\hline F 1 & $\mathrm{P}_{1} \times \mathrm{P}_{3}$ & 304 & 0 & $1: 0$ & - & - \\
\hline $\mathrm{F} 1$ & $\mathrm{P}_{1} \times \mathrm{P}_{4}$ & 302 & 0 & $1: 0$ & - & - \\
\hline F1 & $\mathrm{P}_{2} \times \mathrm{P}_{3}$ & 299 & 0 & $1: 0$ & - & - \\
\hline F 1 & $\mathrm{P}_{2} \times \mathrm{P}_{4}$ & 308 & 0 & $1: 0$ & - & - \\
\hline $\mathrm{F} 1$ & $\mathrm{P}_{3} \times \mathrm{P}_{4}$ & 0 & 317 & $0: 1$ & - & - \\
\hline F2 & $\mathrm{F} 22_{\mathrm{P} 1 \times \mathrm{P} 2}$ & 641 & 0 & $1: 0$ & - & - \\
\hline F2 & $\mathrm{F} 2 \mathrm{P} 1 \mathrm{xP} 3$ & 463 & 164 & $3: 1$ & 0,45 & $50,37 \%$ \\
\hline $\mathrm{F} 2$ & $\mathrm{~F} 22_{\mathrm{P} 1 \times \mathrm{P} 4}$ & 231 & 77 & $3: 1$ & 0,00 & $100 \%$ \\
\hline F2 & $\mathrm{F} 2 \mathrm{P} 2 \mathrm{xP} 3$ & 466 & 133 & $3: 1$ & 2,50 & $11,39 \%$ \\
\hline $\mathrm{F} 2$ & $\mathrm{~F} 2 \mathrm{P} 2 \mathrm{xP} 4$ & 454 & 156 & $3: 1$ & 0,11 & $74,34 \%$ \\
\hline $\mathrm{F} 2$ & $\mathrm{~F} 2 \mathrm{P}_{3 \times \mathrm{P} 4}$ & 0 & 613 & $0: 1$ & - & - \\
\hline $\mathrm{RC}_{1}$ & $(\mathrm{P} 1 \times \mathrm{P} 2) \times \mathrm{P}_{1}$ & 310 & 0 & $1: 0$ & - & - \\
\hline $\mathrm{RC}_{1}$ & $(\mathrm{P} 1 \times \mathrm{P} 2) \times \mathrm{P}_{2}$ & 322 & 0 & $1: 0$ & - & - \\
\hline $\mathrm{RC}_{1}$ & $(\mathrm{P} 1 \times \mathrm{P} 3) \times \mathrm{P}_{1}$ & 308 & 0 & $1: 0$ & - & - \\
\hline $\mathrm{RC}_{1}$ & $(\mathrm{P} 1 \times \mathrm{P} 3) \times \mathrm{P}_{3}$ & 155 & 148 & $1: 1$ & 0,16 & $68,75 \%$ \\
\hline $\mathrm{RC}_{1}$ & $(\mathrm{P} 1 \times \mathrm{P} 4) \times \mathrm{P}_{1}$ & 303 & 0 & $1: 0$ & - & - \\
\hline $\mathrm{RC}_{1}$ & $(\mathrm{P} 1 \times \mathrm{P} 4) \times \mathrm{P}_{4}$ & 105 & 120 & $1: 1$ & 1,00 & $31,73 \%$ \\
\hline $\mathrm{RC}_{1}$ & $(\mathrm{P} 2 \times \mathrm{P} 3) \times \mathrm{P}_{2}$ & 154 & 0 & $1: 0$ & - & - \\
\hline $\mathrm{RC}_{1}$ & $(\mathrm{P} 2 \times \mathrm{P} 3) \times \mathrm{P}_{3}$ & 146 & 149 & $1: 1$ & 0,03 & $86,13 \%$ \\
\hline $\mathrm{RC}_{1}$ & $(\mathrm{P} 2 \times \mathrm{P} 4) \times \mathrm{P}_{2}$ & 308 & 0 & $1: 0$ & - & - \\
\hline $\mathrm{RC}_{1}$ & $(\mathrm{P} 2 \times \mathrm{P} 4) \times \mathrm{P}_{4}$ & 155 & 154 & $1: 1$ & 0,01 & $95,46 \%$ \\
\hline $\mathrm{RC}_{1}$ & $(\mathrm{P} 3 \times \mathrm{P} 4) \times \mathrm{P}_{3}$ & 0 & 317 & $0: 1$ & - & - \\
\hline $\mathrm{RC}_{1}$ & $(\mathrm{P} 3 \times \mathrm{P} 4) \times \mathrm{P}_{3}$ & 0 & 308 & $0: 1$ & - & - \\
\hline
\end{tabular}

* Proporção esperada de plantas tolerantes para plantas sensíveis 
meio do teste do qui-quadrado pela segregação $1: 1$ das plantas oriundas dos retrocruzamentos com o parental sensível. Nas populações de retrocruzamentos com o parental tolerante, $100 \%$ das plantas não apresentaram sintomas visuais de injúrias causadas pelos herbicidas.

Segundo Oliveira Júnior e Inoue (2011), a seletividade de um herbicida depende de diversos fatores, incluindo as condições edafo-climáticas, dosagem e tecnologia de aplicação. Nos experimentos conduzidos, a variação entre as frequências observadas pode ser justificada pela interação desses fatores, uma vez que experimentos em campo sofrem maior influência ambiental. Contudo, a qualidade da condução dos ensaios, a forma de aplicação dos herbicidas e o elevado número de plantas das populações avaliadas permiti-

Tabela 3. Frequências observadas e esperadas para tolerância e sensibilidade ao herbicida tembotrione, e os valores de $\chi^{2}$ e respectivas probabilidades.

\begin{tabular}{|c|c|c|c|c|c|c|}
\hline \multirow{2}{*}{ Geração } & \multirow{2}{*}{$\begin{array}{c}\text { Genótipo } \\
\text { ou } \\
\text { População }\end{array}$} & \multicolumn{2}{|c|}{ Numero de Plantas } & \multirow{2}{*}{$\begin{array}{c}\begin{array}{c}\text { Proporção } \\
\text { Esperada }\end{array} \\
(\mathrm{T}: \mathrm{S})^{*}\end{array}$} & \multirow{2}{*}{$\chi^{2}$} & \multirow{2}{*}{ Probabilidade } \\
\hline & & $\begin{array}{l}\text { Tolerantes } \\
\text { (T) }\end{array}$ & $\begin{array}{l}\text { Sensíveis } \\
\text { (S) }\end{array}$ & & & \\
\hline $\mathrm{P}_{1}$ & CD01_28 & 220 & 0 & $1: 0$ & - & - \\
\hline $\mathrm{P}_{2}$ & CD02_06 & 220 & 0 & $1: 0$ & - & - \\
\hline $\mathrm{P}_{3}$ & CD03_07 & 0 & 208 & $0: 1$ & - & - \\
\hline $\mathrm{P}_{4}$ & $\mathrm{CD}^{-} 4^{-} 72$ & 0 & 211 & $0: 1$ & - & - \\
\hline F1 & $\mathrm{P}_{1} \times \mathrm{P}_{2}$ & 233 & 0 & $1: 0$ & - & - \\
\hline $\mathrm{F} 1$ & $\mathrm{P}_{1} \times \mathrm{P}_{3}$ & 224 & 0 & $1: 0$ & - & - \\
\hline F1 & $\mathrm{P}_{1} \times \mathrm{P}_{4}$ & 228 & 0 & $1: 0$ & - & - \\
\hline $\mathrm{F} 1$ & $\mathrm{P}_{2} \times \mathrm{P}_{3}$ & 213 & 0 & $1: 0$ & - & - \\
\hline $\mathrm{F} 1$ & $\mathrm{P}_{2} \times \mathrm{P}_{4}$ & 232 & 0 & $1: 0$ & - & - \\
\hline $\mathrm{F} 1$ & $\mathrm{P}_{3} \times \mathrm{P}_{4}$ & 0 & 229 & $0: 1$ & - & - \\
\hline F2 & $\mathrm{F} 2_{1.1}$ & 444 & 0 & $1: 0$ & - & - \\
\hline $\mathrm{F} 2$ & $\mathrm{~F} 2_{1.2}$ & 347 & 114 & $3: 1$ & 0,02 & $89,30 \%$ \\
\hline $\mathrm{F} 2$ & $\mathrm{~F} 2_{1.3}$ & 122 & 35 & $3: 1$ & 0,61 & $43,34 \%$ \\
\hline $\mathrm{F} 2$ & $\mathrm{~F} 2_{1.4}$ & 327 & 102 & $3: 1$ & 0,34 & $55,83 \%$ \\
\hline $\mathrm{F} 2$ & $\mathrm{~F} 2_{1.5}$ & 338 & 134 & $3: 1$ & 2,89 & $8,89 \%$ \\
\hline $\mathrm{F} 2$ & $\mathrm{~F} 22_{1.6}$ & 0 & 446 & $0: 1$ & - & - \\
\hline $\mathrm{RC}_{1}$ & $(\mathrm{P} 1 \times \mathrm{P} 2) \times \mathrm{P}_{1}$ & 228 & 0 & $1: 0$ & - & - \\
\hline $\mathrm{RC}_{1}$ & $(\mathrm{P} 1 \times \mathrm{P} 2) \times \mathrm{P}_{2}$ & 229 & 0 & $1: 0$ & - & - \\
\hline $\mathrm{RC}_{1}$ & $(\mathrm{P} 1 \times \mathrm{P} 3) \times \mathrm{P}_{1}$ & 231 & 0 & $1: 0$ & - & - \\
\hline $\mathrm{RC}_{1}$ & $(\mathrm{P} 1 \times \mathrm{P} 3) \times \mathrm{P}_{3}$ & 119 & 98 & $1: 1$ & 2,03 & $15,39 \%$ \\
\hline $\mathrm{RC}_{1}$ & $(\mathrm{P} 1 \times \mathrm{P} 4) \times \mathrm{P}_{1}$ & 230 & 0 & $1: 0$ & - & - \\
\hline $\mathrm{RC}_{1}$ & $(\mathrm{P} 1 \times \mathrm{P} 4) \times \mathrm{P}_{4}$ & 72 & 63 & $1: 1$ & 0,60 & $43,86 \%$ \\
\hline $\mathrm{RC}_{1}$ & $(\mathrm{P} 2 \times \mathrm{P} 3) \times \mathrm{P}_{2}$ & 69 & 0 & $1: 0$ & - & - \\
\hline $\mathrm{RC}_{1}$ & $(\mathrm{P} 2 \times \mathrm{P} 3) \times \mathrm{P}_{3}$ & 114 & 111 & $1: 1$ & 0,04 & $84,15 \%$ \\
\hline $\mathrm{RC}_{1}$ & $(\mathrm{P} 2 \times \mathrm{P} 4) \times \mathrm{P}_{2}$ & 232 & 0 & $1: 0$ & - & - \\
\hline $\mathrm{RC}_{1}$ & $(\mathrm{P} 2 \times \mathrm{P} 4) \times \mathrm{P}_{4}$ & 118 & 115 & $1: 1$ & 0,04 & $84,42 \%$ \\
\hline $\mathrm{RC}_{1}$ & $(\mathrm{P} 3 \times \mathrm{P} 4) \times \mathrm{P}_{3}$ & 0 & 233 & $0: 1$ & - & - \\
\hline $\mathrm{RC}_{1}$ & $(\mathrm{P} 3 \times \mathrm{P} 4) \times \mathrm{P}_{3}$ & 0 & 295 & $0: 1$ & - & - \\
\hline
\end{tabular}

* Proporção esperada de plantas tolerantes para plantas sensíveis 
ram elucidar que o controle genético da tolerância ao nicosulfuron e ao tembotrione é de natureza qualitativa, sendo determinado por um alelo dominante. É importante ressaltar que, independente da ocorrência de diferenças nos níveis de expressão, foi possível realizar a seleção de forma visual.

Um gene com dominância completa conferindo resistência a herbicidas inibidores da enzima Acetolactato Sintase (ALS) também foi verificado por Vargas et al. (2001), mas na planta daninha Euphorbia heterophylla. Em relação às espécies cultivadas, a tolerância tem sido fundamental para o registro desse grupo de herbicidas, o que tem tornado viável a aplicação em cultura importante como o milho.

As bases bioquímicas e moleculares da tolerância aos herbicidas com ação sobre a enzima ALS, grupo que inclui o nicosulfuron, têm sido extensivamente estudadas em plantas daninhas que se tornaram tolerantes a sua aplicação (Hernández et al., 2015). Essa enzima é muito lábil, apresentando-se como isoenzimas em uma variedade de plantas (Shah et al., 2012). Deng et al. (2017) constataram que tanto a posição da mutação no gene ALS e o tipo de aminoácido substituído promovem alterações na estrutura e função da proteína ALS, podendo resultar em diferente atividade enzimática.

Em relação ao herbicida tembotrione, o controle genético da tolerância em milho doce foi descrito como monogênica com variação no grau de dominância (Williams \& Pataky, 2008, 2010). Esse gene foi mapeado no braço curto do cromossomo 5 e estaria associado à regulação da atividade de enzimas do citocromo P450 (Williams \& Pataky, 2008). Em trabalho realizado por Pataky et al. (2009) com o herbicida mesotrione, que apresenta o mesmo grupo químico do tembotrione, foi identificada sensibilidade cruzada com nicosulfuron em linhagens de milho doce, sendo que o controle genético foi atribuído a um gene mapeado no cromossomo 5, associado a pelo menos sete fatores genéticos relacionados à metabolização dos herbicidas, e que se encontram localizados na mesma região genômica dos mutantes nsf1 e ben1 do gene CYP.

Nesse estudo testou-se a hipótese de interação gênica, avaliando-se a resposta das plantas das famílias F3 aos herbicidas nicosulfuron e tembotrione. Dentre essas famílias, 42 foram tolerantes, 47 sensíveis e 100 apresentaram segregação para resposta a esses herbicidas. Por meio do teste $\chi^{2}$ e testando-se a hipótese de segregação 1:2:1 ( $\chi^{2}=0,35$ e Probabilidade $=83 \%$ ) entre famílias F3, foi possível sugerir a ocorrência de co-segregação ou de pleiotropia, uma vez que foram detectadas apenas plantas tolerantes ou sensíveis a ambos os herbicidas dentro das famílias avaliadas. A hipótese de ligação gênica é a mais provável, uma vez que os herbicidas apresentam diferentes mecanismos de ação estando, dessa forma, envolvidos grupos gênicos distintos no controle da expressão da tolerância.

Independente da ocorrência de ligação gênica ou de pleiotropia entre os fatores gênicos envolvidos na tolerância aos herbicidas nicosulfuron e tembotrione, é importante que os alelos que condicionam a sensibilidade sejam eliminados das populações de melhoramento e de cultivares comerciais. As informações obtidas nesse estudo, sendo a tolerância a esses herbicidas qualitativa e de alta herdabilidade, permitiu a introgressão genética de maneira eficiente por meio de retrocruzamento assistido por marcadores moleculares SSR. Nesse contexto, a conversão da linhagem sensível CD03_07, tendo como genitor doador a linhagem tolerante CD02_06 e empregando o RCAM, permitiu identificar plantas tolerantes a ambos os herbicidas contendo de 70 a $97,37 \%$ do 
genoma recorrente em apenas um ciclo de retrocruzamento.

\section{Conclusões}

Existe variabilidade genética na resposta aos herbicidas nicosulfuron e tembotrione, sendo a tolerância conferida por um gene com dominância completa.

O retrocruzamento assistido por marcadores SSR permitiu acelerar o processo de introgressão da tolerância aos herbicidas nicosulfuron e tembotrione em linhagens de milho.

\section{Agradecimentos}

À Cooperativa Central de Pesquisa Agrícola pelo suporte financeiro na realização desse trabalho.

\section{Referências}

CAVALIERI, S. D.; OLIVEIRA JÚNIOR, R. S.; CONSTANTIN, J.; BIFFE, D. F.; RIOS, F. A.; FRANCHINI, L. H. M. Tolerância de híbridos de milho ao herbicida nicosulfuron. Planta Daninha, Viçosa, MG, v. 26, n. 1, p. 203-214, 2008.

DOI: $10.1590 / \mathrm{S} 0100-83582008000100021$.

CAVALIERI, S. D.; SILVA, F. M. L.; VELINI, E. D.; SÃO JOSÉ, A. R.; ULLOA, S. M.; DATTA, A.; CAVALIERI, J. D.; KNEZEVIC, S. Z. Seletividade do nicosulfuron em três estádios fenológicos de milho-pipoca. Planta Daninha, Viçosa, MG, v. 30, n. 2, p. 377-386, 2012.

DOI: $10.1590 / \mathrm{S} 0100-83582012000200017$.

CHRISTOFFOLETI, P. J.; OVEJERO, R. F. L. Resistência das plantas daninhas a herbicidas: definições, bases e situação no Brasil e no mundo. In: CHRISTOFFOLETI, P. J. (Coord.). Aspectos de resistência de plantas daninhas a herbicidas. 3. ed. rev. e atual. Piracicaba: Associação
Brasileira de Ação à Resistência de Plantas Daninhas, 2008. p. 9-34.

CONSTANTIN, J.; OLIVEIRA JÚNIOR, R. S. de; BLAINSKI, E.; HOMEM, L. M. Seletividade e eficácia agronômica do novo herbicida tembotriona para a cultura do milho. In: CONGRESSO BRASILEIRO DA CIÊNCIA DAS PLANTAS DANINHAS, 25., 2006, Brasília, DF. Convivendo com as plantas daninhas: resumos expandidos. Brasília, DF: Sociedade Brasileira da Ciência das Plantas Daninhas: UnB; Planaltina, DF: Embrapa Cerrados, 2006. 1 CD-ROM.

CRUZ, C.; REGAZZI, A. J.; CARNEIRO, P. C. S. Modelos biométricos aplicados ao melhoramento genético. 3. ed. Viçosa, MG: Universidade Federal de Viçosa, 2014. v. 1, $668 \mathrm{p}$.

DAN, H. de A.; BARROSO, A. L.; DAN, L. G. de M.; TANNÚS, V. R.; FINOTTI, T. R. Seletividade de herbicidas aplicados na pós-emergência da cultura do milheto (Pennisetum glaucum). Revista Brasileira de Milho e Sorgo, Sete Lagoas, v. 8, n. 3, p. 297-306, 2009. DOI: 10.18512/1980-6477/rbms.v8n3p297-306.

DAN, H. de A.; BARROSO, A. L. de L.; DAN, L. G. de M.; FINOTTI, T. R.; FELDKIRCHER, C.; SANTOS, V. S. Controle de plantas daninhas na cultura do milho por meio de herbicidas aplicados em pré-emergência. Pesquisa Agropecuária Tropical, Goiânia, v. 40, n. 4, p. 388-393, 2010. DOI: $10.1590 / \mathrm{S} 1983-40632010000400017$.

DÉLYE, C.; JASIENIUK, M.; LE CORRE, V. Deciphering the evolution of herbicide resistance in weeds. Trends in Genetics, Cambridge, v. 29, n. 11, p. 1-10, 2013. DOI: $10.1016 /$ j.tig.2013.06.001.

DENG, W.; YANG, Q.; ZHANG, Y.; JIAO, H.; MEI, Y.; LI, X.; ZHENG, M. Cross-resistance patterns to acetolactate synthase (ALS)-inhibiting herbicides of flixweed (Descurainia sophia L.) conferred by different combinations of ALS isozymes with a Pro-197-Thr mutation or a novel Trp-574-Leu mutation. Pesticide Biochemistry and Physiology, San Diego, v. 136, p. 4145, 2017. DOI: 10.1016/j.pestbp.2016.08.006. 
FERNANDES, E. H.; SCHUSTER, I.; SCAPIM, C. A.; VIEIRA, E. S. N.; COAN, M. M. D. Genetic diversity in elite inbred lines of maize and its association with heterosis. Genetics and Molecular Research, Ribeirão Preto, v. 14, n. 2, p. 6509-6517, 2015. DOI: 10.4238/2015.June.12.3.

HAWKES, T. R. Hydroxyphenylpyruvate dioxygenase (HPPD): the herbicide target. In: KRÄMER, W.; SCHIRMER, U. (Ed.). Modern crop protection compounds. Weinheim: Wiley-VCH, 2007. p. 211-220.

HERNÁNDEZ, M. J.; LEÓN, R.; FISCHER, A. J.; GEBAUER, M.; GALDAMES, R.; FIGUEROA, R. Target-site resistance to nicosulfuron in Johnsongrass (Sorghum halepense) from Chilean corn fields. Weed Science, Champaign, v. 63, n. 3, p. 631-640, 2015.

DOI: 10.1614/WS-D-14-00167.1.

JIANG, G. L. Molecular marker-assisted breeding: a plant breeder's review. In: AL-KHAYRI, J. M.; JAIN, S. M.; JOHNSON, D. V. (Ed.). Advances in plant breeding strategies: breeding, biotechnology and molecular tools. Switzerland: Springer International Publishing, 2015. p. 431-472.

KARAM, D.; SILVA, J. A. A.; PEREIRA FILHO, I. A.; MAGALHÃES, P. C. Características do herbicida tembotrione na cultura do milho. Sete Lagoas: Embrapa Milho e Sorgo, 2009. 6 p. (Embrapa Milho e Sorgo. Circular Técnica, 129).

LIU, X.; XU, X.; LI, B.; WANG, X.; WANG, G.; LI, M. RNA-Seq transcriptome analysis of maize inbred carrying nicosulfuron-tolerant and nicosulfuronsusceptible alleles. International Journal of Molecular Sciences, Basel, v. 16, n. 3, p. 5975-5989, 2015.

DOI: $10.3390 / \mathrm{ijms} 16035975$.

LÓPEZ-OVEJERO, R. F.; FANCELLI, A. L.; DOURADONETO, D.; GARCÍA Y GARCÍA, A.; CHRISTOFFOLETI, P. J. Seletividade de herbicidas para a cultura de milho (Zea mays) aplicados em diferentes estádios fenológicos da cultura. Planta Daninha, Viçosa, MG, v. 21, n. 3, p. 413-419, 2003.

DOI: $10.1590 / \mathrm{S} 0100-83582003000300009$.
OLIVEIRA JÚNIOR, R. S.; INOUE, N. H. Seletividade de herbicidas para culturas e plantas daninhas. In: OLIVEIRA JÚNIOR, R. S.; INOUE, N. H.; CONSTANTIN, J. (Org.). Biologia e manejo de plantas daninhas. Curitiba: Omnipax, 2011. p. 243-262.

PATAKY, J. K.; WILLIAMS, M. M.; RIECHERS, D. E.; MEYER, M. D.Acommon genetic basis for cross-sensitivity to mesotrione and nicosulfuron in sweet corn hybrid cultivars and inbreds grown throughout North America. Journal of the American Society for Horticultural Science, Alexandria, v. 134, n. 2, p. 252-260, 2009.

RUANE, J.; SONNINO, A. Marker-assisted selection as a tool for genetic improvement of crops, crops, livestock, forestry and fish in developing countries: an overview of the issues. In: GUIMARÃES, E. P.; RUANE, J.; SCHERF, B. D.; SONNINO, A.; DARGIE, J. D. Marker-assisted selection: current status and future perspectives in crops, livestock, forestry and fish. Rome: FAO, 2007. p. 3-14.

SHAH, D. M.; GASSER, C. S.; DELLA-CIOPPA, G.; KISHORE, G. M. Genetic engineering of herbicide resistance genes. In: VERMA, D. P. S.; GOLDBERG, R. $B$. (Ed.). Temporal and spatial regulation of plant genes. Wien: SpringerScience \& Business Media, 2012.p.297-312.

TREZZI, M. M.; VIDAL, R. A. Herbicidas inibidores da ALS. In: VIDAL, R. A.; MEROTTO JÚNIOR, A. Herbicidologia. Porto Alegre: Evangraf, 2001. p. 25-36.

VARGAS, L.; BORÉM, A.; SILVA, A. A. Herança da resistência aos herbicidas inibidores da ALS em biótipos da planta daninha Euphorbia heterophylla. Planta Daninha, Viçosa, MG, v. 19, n. 3, p. 331-336, 2001.

DOI: $10.1590 / \mathrm{S} 0100-83582001000300004$.

VELINI, E. D.; OSIPE, R.; GAZZIERO, D. L. P. (Coord.). Procedimentos para instalação, avaliação e análise de experimentos com herbicidas. Londrina: SBCP, 1995.42 p.

WILLIAMS, M. M.; PATAKY, J. K. Genetic basis of sensitivity in sweet corn to tembotrione. Weed Science, Champaign, v. 56, n. 3, p. 364-370, 2008.

DOI: 10.1614/WS-07-149.1. 
WILLIAMS, M. M.; PATAKY, J. K. Factors affecting differential sensitivity of sweet corn to HPPD-inhibitin herbicides. Weed Science, Champaign, v. 58, n. 3, p. 289294, 2010.

DOI: 10.1614/WS-D-09-00058.1.
ZHOU, Q.; LIU, W.; ZHANG, Y.; LIU, K. Action mechanisms of acetolactate synthase-inhibiting herbicides. Pesticide Biochemistry and Physiology, San Diego, v. 89, n. 2, p. 89-96, 2007.

DOI: 10.1016/j.pestbp.2007.04.004. 